\title{
Preliminary Findings On Air Quality Characterisation in the Niger Delta Area of Nigeria
}

[Prof. S.O. Udo and Dr. Igwe O. Ewona]

\begin{abstract}
Preliminary investigation of air quality parameters in Calabar was undertaken by the Atmospheric Research Team at the Department of Physics, University of Calabar under the sponsorship of Tertiary Education Trust Fund, TETFund in Nigeria. The investigation was initially designed to determine air quality indices in three major cities of the oil producing Niger Delta region of Nigeria where gas flaring and other environmental abuse have gone unabated for over four decades. However, due to paucity of funds, the study was limited to Calabar and its environs. This paper is a report of preliminary findings of a comprehensive data collection and analysis of criteria gases and particulate matter in Calabar. Both mobile and stationary equipment were used in the data collection process. The stationary facility consist of AQM65 which was mounted at the geo-environmental field station at the University of Calabar. The station lies at the heart of the city. The automated facility was programmed to record data at a minimum of a minute interval for a period of one year. Records of pollutants such as $\mathrm{SO}_{2}, \mathrm{CO}_{2}, \mathrm{CO}, \mathrm{CH}_{4}, \mathrm{H}_{2} \mathrm{~S}$, NOx, $\mathrm{O}_{3}$, PID, TSP were also uploaded into the cloud automatically. The mobile equipment consist of AEROQUAL series 500 gas analyzer, Aerocet 531S particle mass sampler, Extech 4-1 Environmental meter which were used to measure the concentration of most pollutants and micro climate data for the 50 locations selected for the study. Data is expected to be used to develop air quality indices and air quality map for the area. Preliminary results show six months averages of criteria pollutants indicating that $\mathrm{SO}_{2}$ has $0.003999 p p m, \mathrm{CO}_{2}$ has $0.60606 \mathrm{ppm}, \mathrm{H}_{2} \mathrm{~S}$ has $0.000845 \mathrm{ppm}$, NOx has 0.006034 and $\mathrm{O}_{3}$ has -00223ppm. For particulate matter PM10 has 242.3098ug/m $/ \mathrm{m}^{3}$ while PM2.5 has $59.839 \mathrm{ug} / \mathrm{m}^{3}$. In general, these values are below both international and national standards on air quality further confirming Calabar as the cleanest city in Nigeria.
\end{abstract}

Keywords - Pollution monitoring, environmental degradation, Air quality index, air quality map, Niger Delta

\section{Introduction}

Clean air is considered to be a basic requirement of human health and well-being. However, air pollution continues to pose a significant threat to health worldwide.

Prof. Sunday O. Udo

Department of Physics

,University of Calabar, Calabar

Nigeria

Dr. Igwe O. Ewona

Department of Physics

,University of Calabar, Calabar

Nigeria
According to The World Health Organization WHO assessment, 2006 more than half of the disease burden due to air pollution is borne by the populations of developing countries which account for more than 2 million premature deaths each year. EPA attributes this to growing dirty transportation fleets, expanded and uncontrolled industrial production, and resource extraction especially in SubSaharan Africa. This has been a major cause for concern in Nigerian cities especially in the Niger Delta Region of Nigeria where oil companies have been flaring gas for over four decades with no end in sight. Increased Industrialization, congested urban centers along with increased used of second hand vehicles, poor transportation network, use of fuel wood, electric generators for domestic use, in the face of epileptic power supply which seems to have defied any conceivable Government effort, etc. seems to have further worsened the quality of air in this cities.

And more pathetic is a situation where regulations are hardly enforced. At present there is no organization committed to Air quality monitoring and control except the National Environmental Standards and Regulations Enforcement Agency, NESREA. The Agency is charged with the responsibility of monitoring and regulating activities related to the environment in Nigeria, but has so much such that little or no attention has been given to air quality monitoring and evaluation (NESREA, 2016). At present, the authors are not aware of any permanent or stationary monitoring station in the country. The activities of the organization so far seem to have been confined to demonstrations in selected locations.

The World Health Organization, (WHO, 2016) database on the concentration of fine particulate matter, showed that of the 91 countries selected for urban outdoor air pollution monitoring, Nigeria came out as the 4th worst polluted country in Africa and the 8th in the world. This is worrisome because Nigeria is not only the largest populated country in Africa, it plays a leading role in the political and socio-economic landscape of Africa. Unfortunately too, The United States Environmental Protection Agency, EPA and United Nations Environmental Protection, UNEP intervention in sub-Saharan Africa, SSA does not include Nigeria in any significant way. Leading researchers like OGBA and UTANG (2009) and Mr. Aaron J. Cohen (EPRI, 2005) have underscored the need for more research on long term effects of air pollution on health in developing countries.

Independent research findings are a critical component of accurate data for informed decision making and resource 
Proc. of the Fourth International Conference on Advances in Civil, Structural and Environmental Engineering - ACSEE 2016. Copyright (C) Institute of Research Engineers and Doctors. All rights reserved.

ISBN: 978-1-63248-114-6 doi: 10.15224/ 978-1-63248-114-6-13

materials for further research and development (Fagbeja, 2008 and Abdulkareem, 2011).

\section{Method and Instrumentation}

This project is sponsored Tertiary Education Trust Fund, TETFund and is undertaken as a first step in addressing air pollution issues. The AQM65 acquired from New Zealand, is a state of the art equipment for monitoring and characterizing major air pollutants and micro climate data. It is programmed to record real time data at different time intervals even as low every minute. The following parameters are being measured by the stationary equipment ; Sulfur IV Oxides, $\mathbf{S O}_{2}$; Carbon Dioxide, $\mathbf{C O}_{2}$; Carbon Monoxide, CO; Methane, $\mathrm{CH}_{4}$; Hydrogen ii Sulfise, $\mathrm{H}_{2} \mathrm{~S}$; Oxides of Nitrogen, NOx; Ozone, $\mathrm{O}_{3}$; volatile Organic Compounds VOCs using Photoionization Detectors, PIDs; and Total Suspended Particles, TSP

The data is automatically saved in inbuilt storage modules and uploaded simultaneously into the cloud to avoid human interference, hence guaranteeing data integrity. With an inbuilt Wi-Fi data can be access without normal internet service. Situated at the University of Calabar geoenvironmental field which is almost at the heart of the city makes the site ideal for the study. The station lies at the heart of the city.

In addition to the stationary equipment, the project is designed to undertake extensive air quality monitoring in fifty locations within the city of Calabar. The hand held and mobile equipment consist of AEROQUAL series 500 gas analyzer, Aerocet 531S particle mass sampler, Extech 4-1 Environmental meter and a sound level meter. The gas analyzer measures $\mathrm{SO}_{2}, \mathrm{CO}_{2}, \mathrm{CO}, \mathrm{CH}_{4}, \mathrm{H}_{2} \mathrm{~S} ; \mathrm{NO} 2$ in parts per million

The Particle sampler accounts for fine and coarse particulate matter such as following parameters PM1.0, PM2.5, PM4.0, PM7.0 and PM10.0. in $\mu \mathrm{g} / \mathrm{m}^{3}$.

With the weather instruments we measure wind speed $/ \mathrm{m} / \mathrm{s}$, humidity/\%, air temp/ $/{ }^{\circ} \mathrm{C}$, Light / lumens, sound level/dB, pressure/hpa, and wind direction $/^{\circ}$

\section{Results}

The preliminary results show that:

- Most gases show lower concentration at the onset of the rainy season in March but do not show a clear seasonal pattern which is why the slopes of the regression lines are generally low. Particulate matter in the other hand show seasonal effects. Distortions in this pattern can be attributed to local effects as can be observed from the graphs of Figure 1 to 5 .

- Micro climatic factors show a clear seasonality and an upward trend from December which is the heart of the dry season to July which is at the heart of the rainy season.
- From the associated regression equations we see that: relative humidity has a positive trend while that of surface temperature is negative as expected, Figure 6 and 7.

- Results from the fifty locations show six months averages of criteria pollutants indicating that $\mathrm{SO}_{2}$ has $0.003999 p p m, \mathrm{CO}_{2}$ has $0.60606 \mathrm{ppm}, \mathrm{H}_{2} \mathrm{~S}$ has $0.000845 \mathrm{ppm}$, NOx has 0.006034 and $\mathrm{O}_{3}$ has $00223 \mathrm{ppm}$. For particulate matter PM10 has $242.3098 \mathrm{ug} / \mathrm{m}^{3}$ while PM2.5 has $59.839 \mathrm{ug} / \mathrm{m}^{3}$. In general, these values are below both international and national standards on air quality.

\section{CO DEC -JULY 2016}

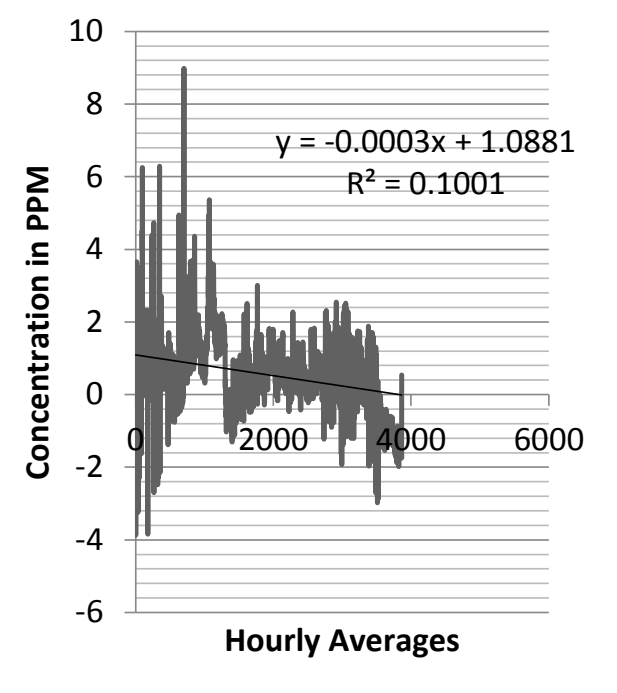

Figure 1. Times Series of Hourly Concentration of CO 
Proc. of the Fourth International Conference on Advances in Civil, Structural and Environmental Engineering - ACSEE 2016. Copyright (C) Institute of Research Engineers and Doctors. All rights reserved. ISBN: 978-1-63248-114-6 doi: 10.15224/ 978-1-63248-114-6-13

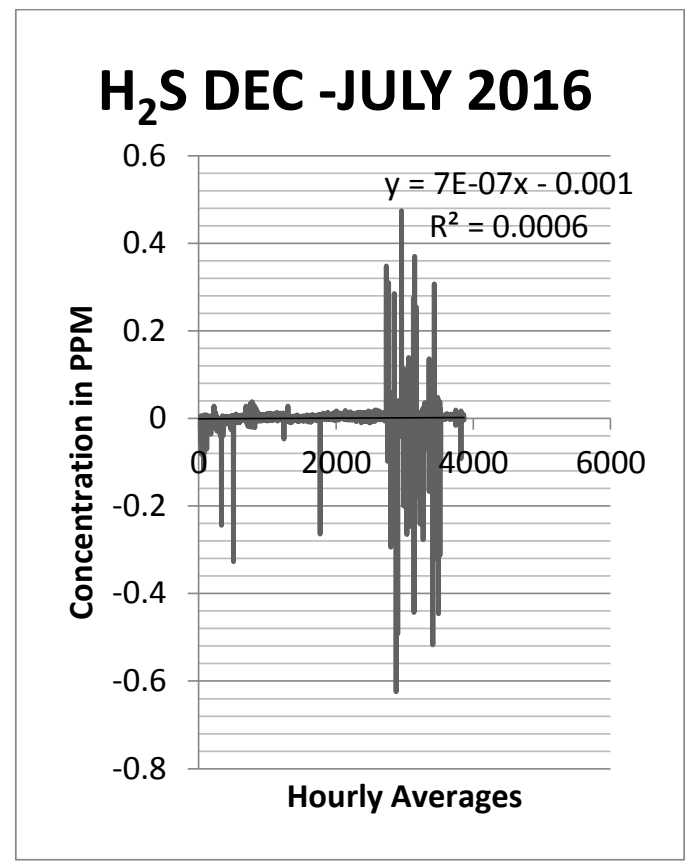

Figure 2. Times Series of Hourly Concentration of $\mathrm{H}_{2} \mathrm{~S}$

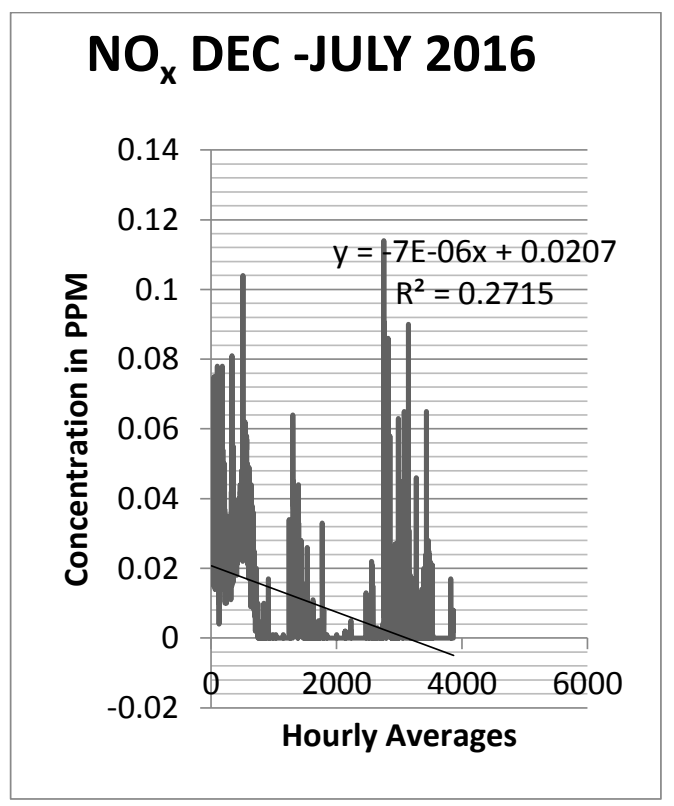

Figure 3. Times Series of Hourly Concentration of $\mathrm{NO}_{\mathrm{x}}$

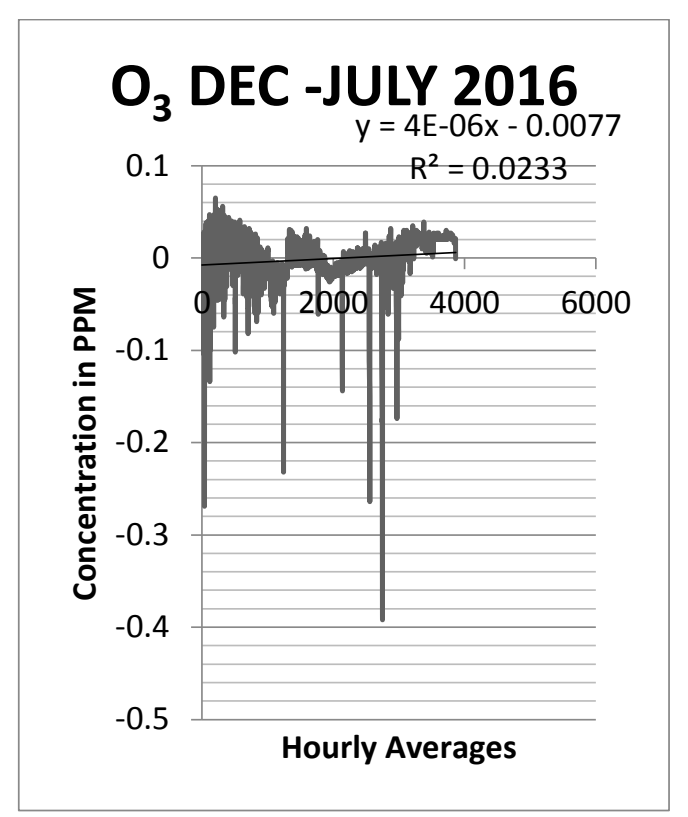

Figure 4. Times Series of Hourly Concentration of $\mathrm{O}_{3}$

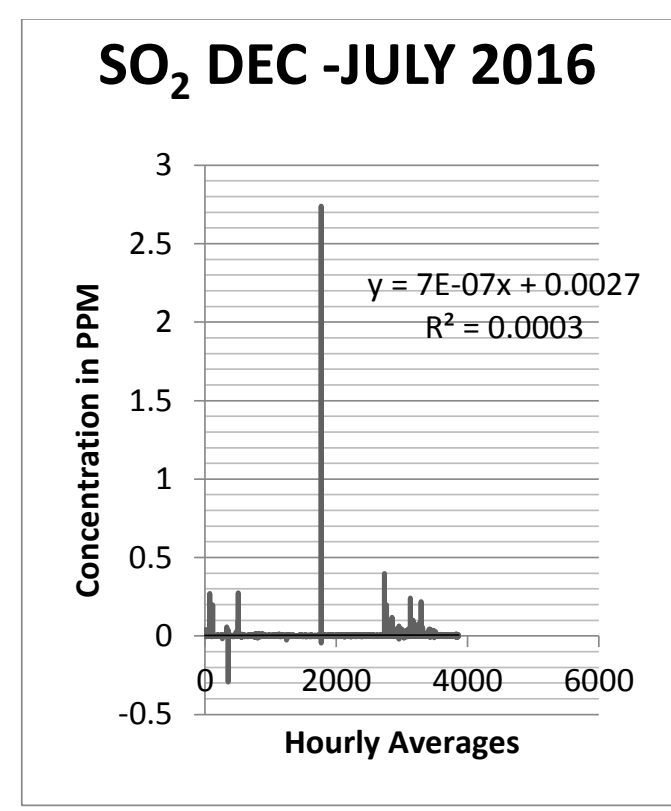

Figure 5. Times Series of Hourly Concentration of $\mathrm{SO}_{2}$ 
Proc. of the Fourth International Conference on Advances in Civil, Structural and Environmental Engineering - ACSEE 2016. Copyright (C) Institute of Research Engineers and Doctors. All rights reserved. ISBN: 978-1-63248-114-6 doi: 10.15224/ 978-1-63248-114-6-13

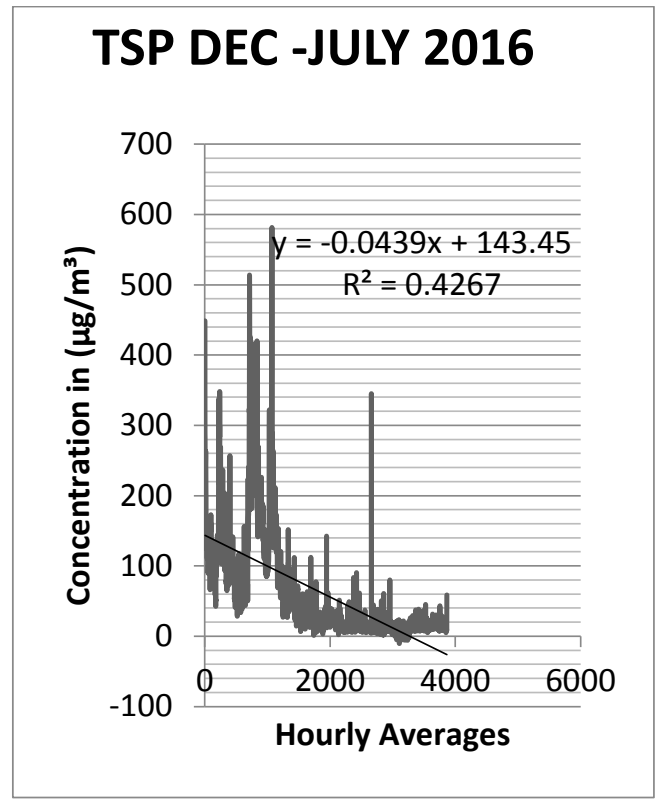

Figure 6. Times Series of Hourly Concentration of TSP

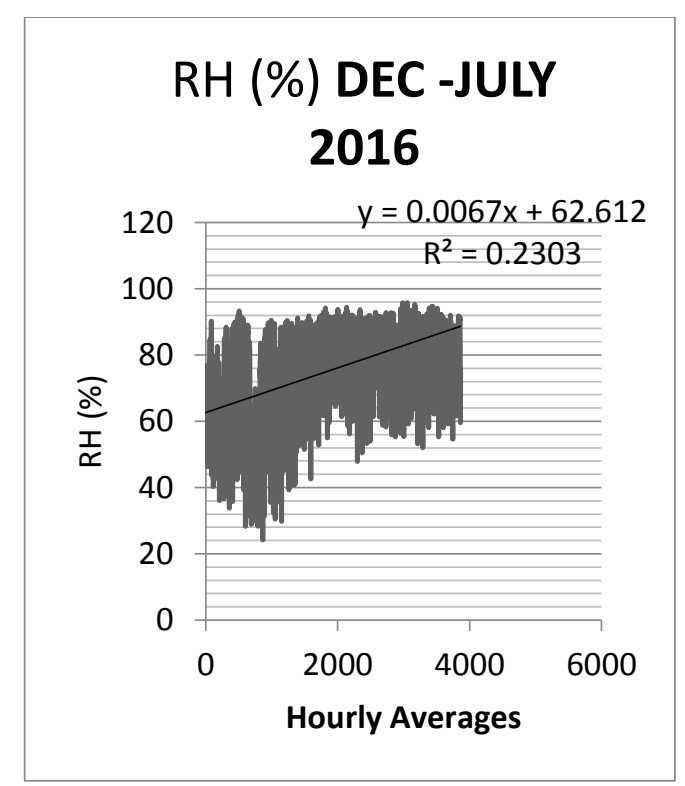

Figure 7. Times Series of Hourly average Relative Humidity

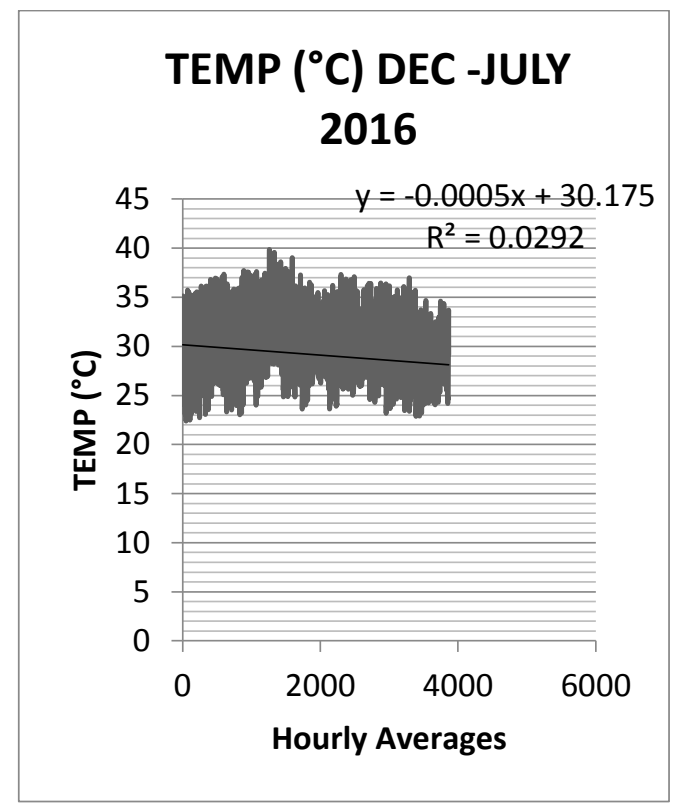

Figure 8. Times Series of Hourly average Temperature

\section{CONCLUSION}

From the above results we can conclude that while the heavy concentration of particulate matter may be due to external factors in the dry season, gaseous pollutants may not be significantly affected by variation in weather and climate.

The average values of criteria pollutants in the fifty locations used for the study show that concentration of criteria gases and particulate matter at both fine and coarse levels are generally below both international and national standards on air quality. As the tourism hub of Nigeria these results may leave Calabar as the cleanest and greenest City in Nigeria.

\section{References}

[1] Abdulkareem (2011). Urban Air pollution Evaluation by Computer Simulation: A case study of petroleum refining company Nigeria, Chemical Engineering Department, Federal University of Technology, Minna Niger State, Nigeria.

[2] Chima Okoko Ogba and B. Pius Utang (2009): Air Pollution Climatology in Spatial Planning for Sustainable Development in the Niger Delta, Nigeria TS 1D - Environment and Land Use Planning

[3] Electric Power Research Institute, EPRI,( 2005). Assessment of Air Quality Impacts on Health and the Environment, April 2005). 
Proc. of the Fourth International Conference on Advances in Civil, Structural and Environmental Engineering - ACSEE 2016. Copyright ( ) Institute of Research Engineers and Doctors. All rights reserved.

ISBN: 978-1-63248-114-6 doi: 10.15224/ 978-1-63248-114-6-13

[4] Mofoluso Fagbeja (2008). Progression Report - Part 1 The progression report submitted in partial EPA 2006,

https://www.bing.com/search?q=air+quality+index+in+Africa\&PC=U 316\&FORM=CHROMN

[5] WHO, 2016. Countries Ranked by Air Pollution http://www.statisticbrain.com/countriesranked-by-air-pollution/ Downloaded $20^{\text {th }}$ Sept 2016 [6] NESREA, 2016 quality.php. Downloaded $22^{\text {th }}$ Sept 2016. 